\title{
Industrial Wastes and Their Management Challenges in Ethiopia
}

\author{
Milkiyas Petros Menbere ${ }^{1 *} \quad$ Timar Petros Menbere ${ }^{2}$ \\ 1.Department of Industrial Chemistry, Ariba Minch University, Ariba Minch, Ethiopia \\ 2.Department of Biotechnology, Addis Ababa Science and Technology University, Addis Ababa, \\ Ethiopia
}

\begin{abstract}
Industrial wastes are useless wastes generated by industrial activities such as manufacturing, fabrication, construction, chemical plants and others. They are among harmful pollutants that affect the environment and water bodies through pollution. In Ethiopia, the rapid industrialization has led to generation of industrial wastes including hazardous ones. But, knowledge of these wastes and their impact on humans and the surrounding environment is very limited. In addition, to minimize the generation of wastes and develop pollution control measures this study has become imperative. Therefore, this review was conducted to examine the different types of industrial wastes, their impacts and their management challenges in Ethiopia. These issues were addressed through exploration of different studies conducted on industrial wastes in Ethiopia and by referring various journals. The study indicated industrial wastes and their impact on the environment were widely prevalent in Ethiopia especially, in Addis Ababa due to abundance of medium and large scale industries compared to other parts of the country. The sources for these wastes include textile and garment industries, tanning industries, beverage industries, industrial parks and others. The wastes from poorly managed industries are contributors to the pollution of both water bodies and different urban areas. Similarly, solid industrial waste management has become a serious challenge that affects the human welfare and the environment in different parts of the country. However, the management of these industrial wastes is inadequate due to absence of treatment plants for each industry, absence comprehensive, integrated and sustainable solid waste management plan, problem with rapid growth of population and insufficient resources to deal with industrial waste management issues.
\end{abstract}

Keywords: Industrial Wastes, Management, Challenge, Ethiopia.

DOI: $10.7176 / \mathrm{CMR} / 11-8-01$

Publication date:October $31^{\text {st }} 2019$

\section{Introduction}

Waste is any byproduct that results from consumer-based lifestyles (Hoornweg and Bhada-Tata, 2012). It comprises municipal solid wastes, industrial wastes, medical wastes, radioactive wastes, etc. Industrial wastes makeup $94 \%$ of all wastes and are generated by industrial activities such as manufacturing, fabrication, construction, chemical plants and others (Links, 2006; Hoornweg and Bhada-Tata, 2012). Industrial wastes are wastes considered as useless occurring during a production process and exist in solid, liquid and gaseous states. Humans pollute their environment with these industrial wastes (Mekonnen, 2012).

Industrial solid wastes are mostly visible, unusable materials generated and derived from industrial activities in a given industrial area (Hoornweg and Bhada-Tata, 2012; Mekonnen and Gokcekus, 2019). These unwanted industrial wastes are various types and are categorized according their origin and products (Same, 2017; Mekonnen and Gokcekus, 2019). They are one of the most harmful pollutants and if they are uncollected, they lead to environmental pollution (Hoornweg and Bhada-Tata, 2012). Similarly, in now days, industrial waste water is increasing from time to time associated with industrial expansion in cities. As a result, industries have become the common source of water pollution (Firdissa et al., 2016).

Industrialization is the back bone for development as it contributes for economic growth and human welfare. However, the ever-increasing industrial activities lead to environmental pollution and ecosystem deterioration globally. Especially, untreated and partially treated industrial wastes are the major threats for water ecosystems (Firdissa et al., 2016). In Ethiopia, the rapid industrialization has led to the generation of industrial wastes including the hazardous ones (Teku, 2006). Improper management of vast amount of industrial wastes is one of the most critical environmental problems in Ethiopia, especially, in Addis Ababa (Firdissa et al., 2016).

Although the number of industries in Ethiopia is few, their impact in terms of pollution is enormous. This is due to the majority of industries lack treatment plants and discharges their waste in the form of liquid, dust particles and smoke (Fenta, 2014). But, studies on types of industrial wastes, their impacts and management challenges are inadequately discussed in Ethiopia. For instance, there are hardly any detailed and comprehensive national water risk assessment studies conducted on Ethiopia's textile and garment sector so far. Thus, knowledge of impacts from industrial effluent on humans and the surrounding environment is very limited (Sima and Restiani, 2018). In addition, it has become imperative to reduce and minimize generation of wastes and develop pollution control measures required to mitigate further contamination of the environment (Teku, 2006; Teklu, 2012). This necessitates an effective management of wastes at the various stages of its generation, storage, collection, transfer 
and transport, processing, and disposal and recycling in an environmentally sound manner in accordance with the best principles of public health, economics, engineering, conservation, and aesthetics (Hailemariam and Ajeme, 2014). Therefore, this paper aimed to examine the different types of industrial wastes and their management challenges in Ethiopia so as to identify the sources for industrial wastes, assess their impacts and distinguish their management challenges.

\section{Distribution of industrial wastes in Ethiopia}

Similar to other cities in developing countries, Addis Ababa is one of the main city in which industrialization is highly expanded in Ethiopia. Most of the medium and large scale industries in Ethiopia (more than 65\%) are located in Addis Ababa and the nearby town of Akaki (CSA 1999). As a result, industrial wastes and their impact on environment are widely prevalent in Addis Ababa compared to other parts in the country (Firdissa, et al., 2016). This is due to most industries were established without environmental impact assessment and almost all industries in the city are located in the vicinity of water course and among them about $90 \%$ simply discharging their effluent in to the nearby river (Teklehaimanot, 2005). In addition, improper management of wastes generated by various industrial activities and absence of proper waste water treatment plant intensified environmental problems in the country. This leads to major impact in the environment, due to toxic substances like heavy metals and solvents discharge to water bodies (Firdissa, et al., 2016).

Relative contribution of industrial wastes for municipal solid waste generation

Although detail studies are lacking on industrial solid wastes to assess their contribution for municipal solid wastes in the country, it has been identified that industrial wastes are among the contaminants to the environment. For example, in Addis Ababa, industrial wastes contribute for 5\% solid organic waste production according to the study by (Regassa et al., 2011; Mohammed and Eyasu, 2017). Similarly, wastes from small scale industries were also among the sources of municipal solid wastes in both Gondar and Hossana Towns (Table 1 and 2).

Table 1. Major solid waste sources and their annual generation of Gondar Town in 2013

\begin{tabular}{|l|l|l|l|}
\hline No & Sources of SW generation & Per year in Kg & Contribution in \% \\
\hline $\mathbf{1}$ & Residential areas & 2930400 & 69.81 \\
\hline $\mathbf{3}$ & Commercial and Street areas & 950300 & 22.64 \\
\hline $\mathbf{3}$ & Industries & 64900 & 1.55 \\
\hline $\mathbf{4}$ & Institutions & 252000 & 6.00 \\
\hline & Total & 4197600 & $100 \%$ \\
\hline
\end{tabular}

Source: (Gedefaw, 2015).

According to the above table, industrial wastes contribute for $1.5 \%$ of overall waste production in Gondar Town. There is an increase of industrial solid waste generation in Ethiopia related to the recent development in the industry sector. Similarly, the study conducted by (Same, 2017), indicates the contribution of industrial solid wastes for municipal solid waste generation in other town in Ethiopia. Accordingly, industry contributes for over six percent of solid waste generation in the Hossana Town municipality.

Table 2. Solid waste generation rate of Hossana Town

\begin{tabular}{|l|l|l|l|}
\hline No & Sources of SW generation & Per year in Kg & Contribution in \% \\
\hline 1 & House holds & $8,974,600$ & 6.59 \\
\hline 2 & Hotels, Café and Restaurants & $16,901,100$ & 12.41 \\
\hline 3 & Industry & $9,271,200$ & 6.81 \\
\hline 4 & Institutions & $94,289,100$ & 69.25 \\
\hline 5 & Commercial areas & $6,721,900$ & 4.94 \\
\hline \multicolumn{2}{|l}{ Total } & $136,157,900$ & $100 \%$ \\
\hline
\end{tabular}

Source: (Same, 2017).

\section{Attributes and types of industrial wastes in Ethiopia Effluents from textile and garment industries}

Environmental pollution from manufacturing plants is a big concern in Ethiopia which is similar to most of developing countries. Especially, industrial waste is difficult to water bodies since it affects the water ecosystems through chemicals before and after the process of production (Mekonnen and Gokcekus, 2019). Textile and garment manufacturing plants are among the industries that demand high amount of water for their production. As a result, they generate high amount of liquid waste. Many of the textile and garment factories in Ethiopia do not possess waste treatment plants to properly dispose their wastes (Fenta, 2014). They merely dispose their effluent directly to their environment, which in most cases are water bodies. As a result, from some studies conducted on small number of individual textile factories, it was reported that the wastewater from the textile and garment sector in Ethiopia is possibly the largest source of industrial soil and water pollution (Sima and Restiani, 2018). Although 
Ethiopia has regulations for controlling the different environmental impacts of industrial wastes, the problem of enforcing rules and absence of adequate government supervision intensified the problem (Sima and Restiani, 2018).

\section{Wastes from tanning industries}

Tanning industries are among the industries that produce high concentrations of toxic metals and pollute the water bodies (Fig 1a). The presence of leather processing industries intensified the accumulation of toxic metals mainly chromium in the study conducted on Akaki river catchment. Lead and Cadmium were also among the toxic metals that made the proportion of pollutants of the river (Mengesha et al., 2017). In the same way, a study conducted in Sheba Leather Industry in Wukro (Ethiopia) indicated the physical composition of the tannery solid wastes generated. The wastes that were identified by physical observation included: shacked salt, raw trimmings, fleshings, hair waste, splitting waste, shavings, crust and leather trimmings. In addition, other solid wastes and sludges, were also produced during the wastewater treatments in the area (Framis, 2018).

\section{Wastes from beverage industries}

Many rivers in Ethiopia are prone to pollution resulted from discharge of wastewater from industry. This is particularly the case for the rivers in Addis Ababa. Beverage industries are among these industries that have a great contribution for the discharge of wastewater effluent to the nearby rivers. The rivers in Addis Ababa are contaminated with different organic and inorganic pollutants emanated from these sources (Abrha and Chen, 2017).

\section{Wastes from industrial parks}

Currently, industrial parks are important options being implemented to enhance industrialization in Ethiopia. Despite the different benefits they provide, they are also sources of pollution. According to the study conducted in Bole Lemi Industry Park, it was found that there were high concentrations of toxic heavy metals such as lead (4.97 $\mathrm{mg} / \mathrm{kg})$ and cadmium $(22.7 \mathrm{mg} / \mathrm{kg}$ ) related to activities within the park. This revealed that examined sludge samples contained are relatively higher amount of heavy metals compared to ambient Ethiopian environmental standards of soil, and indicate pollution of the environment (Delelegn, 2018).

\section{Wastes from other industries}

These are wastes that include highly heterogeneous mass of discarded materials from different scale of industrial activities (Fig 1b). These wastes are commonly seen in Addis Ababa City. The sources for these industrial wastes include food industries (Kality Foods), metal production industries (Kality Metal Products Factory and Ethiopian Iron and Steel Factory), paper production industries (MAMCO Paper Products Factory), chemical industries and pharmaceuticals (Kadisco Chemical Industry and Pharmaceuticals) and others (Teku, 2006). Similarly, wastes from small scale industries also contribute for solid wastes in both Hossana and Gondar Town (Same, 2017; Gedefaw, 2015).

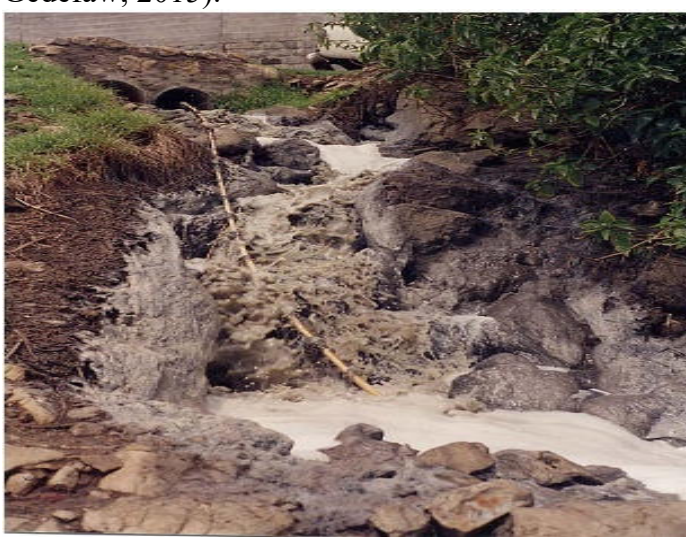

Fig 1. a) Waste from tannery sources polluting the Akaki River (Teklehaimanot, 2005).

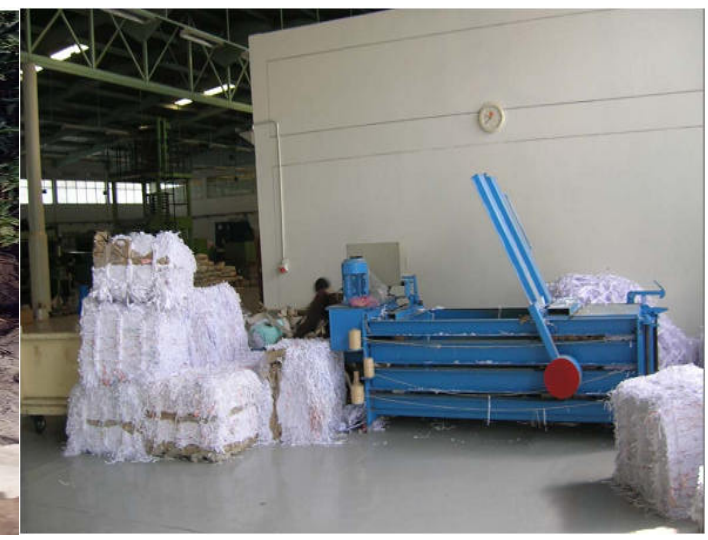

b) Solid wastes generated at Mamco

Paper Products Company (Teku, 2006).

\section{Impacts of industrial wastes in Ethiopia}

Pollution due to industrial activities is increasing in developing countries and this led to problem of waste disposal in these areas (Abrha and Chen, 2017). This makes industrialization to be the source for increasing amount of solid waste and main agent to environmental degradation in these countries (Yalew, 2012). Similarly, worldwide more than half of the population of developing countries does not have access to sanitation and more than $80 \%$ of the 
waste water generated is directly discharged into surface and ground water bodies (Manderso, 2018). In Ethiopia, the effects of industrial wastes are increasing from time to time and their impacts are described as follows.

\section{Impacts on the water bodies and ecosystems}

In Ethiopia, surface and groundwater pollution are not considered as such a major problem until recently. But, the environmental qualities of freshwater ecosystems are deteriorated by pollutants. Pollution of water bodies from industrial wastewater and toxic chemicals are among the factors for their pollution (Tarekegn and Truye, 2018). Industrial waste from poorly managed industries is an important contributor to the pollution of water bodies especially rivers in Ethiopia (Teklehaimanot, 2005; Angassa, 2011). This is due to most of the factories in Ethiopia have no wastewater treatment plants (Alayu and Yirgu, 2018). As a result, industries in Ethiopia, mostly dispose their untreated toxic wastewater simply into the nearby rivers, lakes and streams. This has accelarated pollution from industrial wastewater discharge through nutrients and toxic substances (Alayu and Yirgu, 2018).

Disposal of direct industrial wastes to water bodies have different consequences. It changes the BOD and COD of rivers. It also changes the concentration of iron, manganese, zinc, chromium, lead, and cadmium in water ecosystems (Mengesha et al 2017). Releasing industrial waste to rivers elevates the heavy metals concentration such as Lead $(\mathrm{Pb})$, Nickel $(\mathrm{Ni})$, Cadmium $(\mathrm{Cd})$ and Chromiu $(\mathrm{Cr})$, and enhance pollution as evidenced by the study on Tikur Wuha River in Hawassa, Ethiopia (Fenta, 2014). Similarly, the findings from the study conducted on Bahir Dar Textile Factory Effluents indicated the presence of different impacts and deterioration of water quality conditions of the head of Blue Nile River, in Bahir Dar, Ethiopia (Mehari et al. 2015).

Industrial wastes also affect human welfare in addition to their impact on the environment. For instance, increased industrial wastes lead to pollution stress on surface water (Ajayi and Osibanjo, 1981). This in turn affects the provision safe water supply for communities when the local sources ran dry or became polluted. It also leads to low water supply coverage system and poor sanitation services (Manderso, 2018). Utilizing polluted river water by downstream residents for agriculture and other activities exposes for different social problems (Abrha and Chen, 2017). This is the case of rivers in and around Addis Ababa as the locals who are dependent on these water sources are being affected by untreated industrial wastewaters discharge released directly to these rivers (Teklehaimanot, 2005).

\section{Impacts of solid industrial wastes on municipality}

Solid industrial wastes are throwaway from different industrial based activities. They are discharged during the different production processes. These wastes can be corrosive (that are capable of corrode metal containers such as tanks), ignitable (that can create fires), reactive (which are unstable in nature, they cause explosions, toxic fumes when heated), and toxicity (which are harmful or fatal when ingested or absorb) (Yalew, 2012). In many developing countries solid industrial waste management has become a serious challenge (Abebe, 2018). This is also the case in Ethiopia, associated with industrialization coupled with increased urban populations that cause pressure on management of the ever increasing amounts of solid wastes. But recently, people in Ethiopia have become aware of the negative consequences of poor solid waste management (Hailemariam and Ajeme, 2014).

The diverse sources of solid waste generation and the complex nature of its composition make the management of solid waste difficult. As a result, governments and municipalities are facing considerable difficulties to provide adequate solid waste management (SWM) services in Ethiopia (Hailemariam and Ajeme, 2014). In Addis Ababa for instance, approximately, 1200 large industrial enterprises are found and contribute for 18\% of overall solid wastes in the city together with institutions, commercial center and hotels (Assnakew, 2017; Addis Ababa City Adminstration, 2010). The number, nature and capacity of the industries vary across the sub cities, but large majorities are located in Nefas Silk, Yeka and Akaki Kality sub cities. Most industries generate toxic, corrosive and explosive hazardous wastes that are highly pollutants to humans and their environment (Assnakew, 2017).

\section{Challenges of industrial waste management in Ethiopia}

With a rapidly expanding population and a growing trend of industrial development, problems related to industrial waste management are increasing in Ethiopia. Especially, the problem is more severe in Addis Ababa the capital where most of the industrial establishments of the country are taking place. However, among the existing industries operating in the city only a few of them treat their wastes to any degree while the majority discharges their wastes into nearby water bodies without any treatment (Teku, 2006). In the same way, the city does not have a comprehensive, integrated and sustainable solid waste management plan to effectively respond to the complexities associated with such dynamics (Assnakew, 2017).

The rapid growth of industry has accelerated the generation of industrial, hazardous/toxic dynamics in Ethiopia (Assnakew, 2017). Industrial pollution control measures are needed to mitigate further contamination of water, soils and crops with especially heavy metals (Teklu, 2012). Unfortunately, like other developing countries, Ethiopia does not possess sufficient resources to deal with this and other serious environmental issues (Teku, 2006). 


\section{Conclusion}

Industrial wastes are wastes considered as useless and are generated by industrial activities. In Ethiopia, the rapid industrialization has led to the generation of industrial wastes including the hazardous ones. The different industrial wastes affect humans and their environment in Ethiopia mainly, in Addis Ababa. The sources for these industrial wastes are textile and garment industries, tanning industries, beverage industries and industrial parks. These industrial wastes affect humans, urban areas and the environment in different ways. However, management activities to reduce and control these industrial wastes were not adequately implemented due to absence of treatment plants for each industry, absence comprehensive, integrated and sustainable solid waste management plan, problem with rapid growth of population and insufficient resources to deal with industrial waste management issues.

\section{Reference}

Abebe, M. A. (2018). Challenges and practice of Plastic Bottles, paper and carton Generation and Collection in Addis Ababa City, Ethiopia. Amer. J. Res. (2018): 117-132.

Abrha, B.H. and Chen, Y.J. (2017). Analysis of Physico-Chemical Characteristics of Effluents from Beverage Industry in Ethiopia. J. Geosc. Env. Prot., 5, 172-182.

Addis Ababa City Adminstration (2010). Overview of Addis Ababa City Solid Waste Management System. Addis Ababa City Adminstration, Addis Ababa.

Ajayi, S.O. and Osibanjo, O. (1981). Pollution Studies on Nigeria Rivers, II. Water Quality of Some Nigeria Rivers. Environmental Pollution Series B, Chem. Phys., 2, 87-95.

Alayu, E. and Yirgu, Z. (2018). Advanced technologies for the treatment of wastewaters from agro-processing industries and cogeneration of by-products: a case of slaughterhouse, dairy and beverage industries. Int. J. Environ. Sci. Techn. 15:1581-1596.

Angassa, K. (2011). Evaluation of the performance of constructed wetland system for the treatment of brewery wastewater. MSc. Thesis, Addis Ababa University, Addis Ababa.

Assnakew, M. (2017). Study of Hazardous Industrial Waste Management Practices and development of Hazardous Industrial Waste Management Guidelines in Addis Ababa. Int. J. Sci. Engin. Sci., 1 (8): 33-39.

Central Statistic Authority, CSA (1999). Statistical Abstracts: 1999, CSA, Addis Ababa.

Delelegn, G.M. (2018). Assessment of Physical and Chemical Contents of Textile Sludge and Associated Risks on Public Health: In Case of Common Efflent Treatment Plant (CETP). J. Ecol. Env. Sci., 6 (1): 21-26.

Fenta, M. M. (2014). Heavy metals concentration in effluents of Textile industry, TikurWuha River and Milk of cows watering on this water source, Hawassa, Southern Ethiopia. R. J. Env. Sci. 8 (8): 422-434.

Firdissa, B., Solomon, Y. and Soromessa, T. (2016). Assessment of the Status of Industrial Waste Water Effluent for Selected Industries in Addis Ababa, Ethiopia. J. Nat. Sci. Res., 6 (17): 1-10.

Framis, C. P. (2018). Assessment of tannery solid waste management; A case of Sheba Leather Industry in Wukro (Ethiopia). Report Paper, UPC and ETSEIB, pp.1-92.

Gedefaw, M. (2015). Assessing the Current Status of Solid Waste Management of Gondar Town, Ethiopia. Int. J. Sci. Techn. Res., 4 (09): 28-36.

Hailemariam, M. and Ajeme, A. (2014). Solid Waste Management in Adama, Ethiopia: Aspects and Challenges. Int. J. Env. Ecol. Engin., 8 (9): 670-676.

Hoornweg, D. and Bhada-Tata, P. (2012). What a Waste. A Global Review of Solid Waste Management. Urban Development and Local Government Unit, World Bank, Washington, DC. Report Document, No. 15, Www.Worldbank.Org/Urban.

Links, J.M. (2006). Municipal, Industrial, and Hazardous Waste, The Johns Hopkins University, pp. 1-70.

Manderso, T. M. (2018). Overview of Existing Wastewater Management System in Case of Debre Markos Town, Ethiopia. Engin. Math., 2 (2): 107-118.

Mehari, A. K., Gebremedhin, S. and Ayele, B. (2015). Effects of Bahir Dar Textile Factory Effluents on the Water Quality of the Head Waters of Blue Nile River, Ethiopia. Int. J. Anal. Chem., (2015): 1-7.

Mekonnen, F. H. (2012). Liquid waste management: The case of Bahir Dar, Ethiopia. Ethiop. J. Heal. Dev., 26 (1): 49-53.

Mekonnen, Y. A. and Gokcekus, H. (2019). Urbanization and Solid Waste Management Challenges, in Addis Ababa City, Ethiopia. Civ. Env. Res., 11(5): 6-15.

Mengesha, S. D., Kidane, A. W., Teklu, K. T., Gizaw, M., Abera, D., Getachew, M., Abate, M., Beyene, Y., Assefa, T. and Alemu, Z. A. (2017). Contamination Effect on Pollution Status of Akaki River and Its Contamination Effect on Surrounding Environment and Agricultural Products: Ministry of health and Ethiopian public health institute, Technical Report, pp. 1-49.

Mohammed, A. and Eyasu, E. (2017). Domestic solid waste management and its environmental impacts in Addis Ababa city. J. Env. Wast. Manag., 4(1):194-203.

Regassa, N., Sundaraa, R.D. and Seboka, B.B. (2011). Challenges and Opportunities in Municipal Solid Waste 
Management: The Case of Addis Ababa City, Central Ethiopia. J. Hum. Ecol., 33(3): 179-190.

Same, T. L. (2017). Practices and Challenges of Solid Waste Management in Hossana Town, Southern Ethiopia. MSc Thesis, Ariba Minch University, Ariba Minch.

Sima, S. and Restiani, P. (2018). Water Governance Mapping Report: Textile Industry Water Use in Ethiopia. SIWI and STWI, pp. 1-31.

Tarekegn, M.M. and Truye, A. Z. (2018). Causes and impacts of Shankila River water pollution in Addis Ababa, Ethiopia. Environ. Ris. Ass. Remediat., 2(4):21-30.

Teklehaimanot, R. R. (2005). Program on the sustainable consumpion and production in the Akaki River Basin. A situation Analysis of the Akaki River. The Ethiopian Science and Technology Comission (ESTC), United Nations Environment Programme (UNEP) and The Ethiopian Cleaner Production Center (ECPC). Final Report, pp. 1-99.

Teklu, S. (2012). Wastewater Production, Treatment, and Agricultural Use in Ethiopia: The Case of Addis Ababa. Third Regional Workshop 'Safe Use of Wastewater in Agriculture', 26-28 September 2012, Johannesburg.

Teku, G. T. (2006). Industrial Waste Management Practices in Addis Ababa: A Case Study on Akaki - Kality Industrial Zone, Ethiopia. MSc Thesis, Addis Ababa University, Addis Ababa.

Yalew, A. W. (2012). Do institutional factors matter for improved solid waste management? Munich Personal RePEc Archive MPRA Paper No. 42894, pp. 1-16. 